\title{
How Are Dysplastic Hips Different? A Three-dimensional CT Study
}

\author{
Harold van Bosse MD, John H. Wedge MD, \\ Paul Babyn MD
}

Received: 24 July 2014/ Accepted: 9 December 2014/Published online: 19 December 2014

(C) The Association of Bone and Joint Surgeons (B) 2014

\begin{abstract}
Background Surgical correction of acetabular dysplasia can postpone or prevent joint degeneration. The specific abnormalities that make up the dysplastic hip are controversial.

Questions/purposes (1) What are the relative size, shape, and orientations of the typical nondysplastic hip? (2) How do these variables differ in the developmentally dysplastic hip? (3) Are there version differences between the acetabuli of dysplastic and nondysplastic hips? (4) Are there pairs of variables in which the change in one is always
\end{abstract}

Each author certifies that he or she, or a member of his or her immediate family, has no funding or commercial associations (eg, consultancies, stock ownership, equity interest, patent/licensing arrangements, etc) that might pose a conflict of interest in connection with the submitted article.

All ICMJE Conflict of Interest Forms for authors and Clinical Orthopaedics and Related Research ${ }^{\circledR}$ editors and board members are on file with the publication and can be viewed on request.

Clinical Orthopaedics and Related Research ${ }^{\circledR}$ neither advocates nor endorses the use of any treatment, drug, or device. Readers are encouraged to always seek additional information, including FDA-approval status, of any drug or device prior to clinical use. Each author certifies that his or her institution approved the human protocol for this investigation and that all investigations were conducted in conformity with ethical principles of research.

This work was performed at the Hospital for Sick Children, Toronto, Ontario, Canada.

H. van Bosse ( $\square)$

Shriners Hospitals for Children-Philadelphia, 3551 N Broad

Street, Philadelphia, PA 19140, USA

e-mail: hvanbosse@shrinenet.org

J. H. Wedge

Hospital for Sick Children, Toronto, ON, Canada

P. Babyn

Royal University Hospital, Saskatoon, SK, Canada accompanied by a change in the other for both nondysplastic and dysplastic acetabuli?

Methods Of 117 consecutive three-dimensional (3-D) CT scans performed for hip dysplasia between March 1988 and October 1995, 48 met criteria of developmentally dysplastic hips by plain radiography. These were retrospectively compared with 55 pelvic 3-D CT scans culled from 81 consecutive scans performed for reasons other than hip dysplasia (ie, hip pain, trauma, infection) that did not affect the hip or pelvic landmarks. The 3-D reconstructions were orientated anatomically for standardization of the measurements to be compared. Representative 3-D volumes of the acetabular space were constructed from which we could measure anatomic positions and dimensional information. One author performed all image orientation and measurements. Results Nondysplastic acetabuli are essentially hemispheric with height equal to width and twice the depth. The dysplastic acetabuli were elongated in females (52.4 \pm $6.2 \mathrm{~mm}$ for dysplastic versus $46.5 \pm 4.6 \mathrm{~mm}$ for nondysplastic (mean difference, 5.0; 95\% confidence interval [CI], 1.9-8.0; $\mathrm{p}=0.002$ ) and shallower in both females $(18.7 \pm 4.9 \mathrm{~mm}$ for dysplastic versus $23.6 \pm 4.0 \mathrm{~mm}$ for nondysplastic; mean difference, 6.5 ; 95\% CI, 4.4-8.5; $\mathrm{p}<0.0001)$ and males $(21.1 \pm 4.8 \mathrm{~mm}$ for dysplastic versus $25.0 \pm 4.3 \mathrm{~mm}$ for nondysplastic, mean difference, 5.3 ; $95 \% \mathrm{CI}, 2.6-8.1 ; \mathrm{p}=0.0002$ ); width was similar to that of nondysplastic hips. Acetabular openings were slightly more vertical than nondysplastic hips in females $\left(5^{\circ} ; 95 \% \mathrm{CI}, 1.9-8.1 ; \mathrm{p}=0.002\right)$ but not in male subjects. The dysplastic acetabuli were smaller in volume $(18 \%$ in females, $p=0.002$, and $19 \%$ in males, $p=0.0012$ ) and had less space occupied by the femoral head compared with nondysplastic hips $(\mathrm{p}<0.0001$ for females, $\mathrm{p}<0.0001$ for males). Dysplastic hip midacetabulum was $4^{\circ}$ more anteverted in females $(95 \%$ CI, 0.5-6.8; 
$\mathrm{p}=0.022$ ) but not for males $(\mathrm{p}=0.538)$. The upper dysplastic acetabulum was more retroverted in females and males $\left(10.2^{\circ} ; 95 \% \mathrm{CI}, 5.5-15 ; \mathrm{p}<0.0001\right.$, and $7.0^{\circ} ; 95 \%$ CI, 0.6-13.4; $\mathrm{p}=0.032$, respectively). Acetabular volumes in nondysplastic and dysplastic hips were related to acetabular width but not to length.

Conclusions Developmentally dysplastic acetabuli are not deficient in merely a single dimension but are globally deficient. The subluxated femoral head lies in the elongated and retroverted superior acetabulum, which becomes progressively shallower as the acetabulum increases in length. Focally deficient anterior or posterior femoral head coverage is uncommon. Current procedures that redirect the acetabulum, no matter how technically successful, cannot fully compensate for the incongruence of a spherical femoral head within a shallow and elongated acetabulum unless corrected at an early age when acetabular remodeling is possible. Early detection and treatment of acetabular dysplasia should be emphasized.

Level of Evidence Level III, prognostic study.

\section{Introduction}

Acetabular dysplasia causes a focal concentration of contact stress on the articular cartilage $[16,17,26]$, which can eventually lead to osteoarthritis (OA) [50, 51]. Hip OA secondary to uncorrected hip dysplasia is the most common reason for hip arthroplasty in young adults [7, 10, 23, 51]. Procedures to correct acetabular orientation may delay the onset and/or progression of OA [16, 43, 49, 52, 53, 55, 61, 69]. These procedures are designed to decrease high articular cartilage load by repositioning the acetabulum to maximize the femoral-acetabular contact surface and femoral head coverage [26, 29, 45, 47]. To position the acetabulum correctly, it is important to understand how the pathological anatomy and orientation of the dysplastic acetabulum differ from that of the typical nondysplastic hip.

Dysplastic hip anatomy has become better understood with the advent of newer imaging technologies. Whereas plain radiographs demonstrate superolateral subluxation, axial CT scans make it possible to quantify abnormalities in acetabular orientation and define acetabular defects of the anterior and posterior walls [14, 56, 72]. Since the mid-1980s, computer software has been available to summarize serial CT scan images, producing twodimensional (2-D) reconstructions and three-dimensional (3-D) surface volumes [42, 67, 70]. The 3-D CT scan has enhanced the ability to assess femoral head coverage and the shape of the acetabulum, improving spatial visualization over 2-D scans [8, 31-33, 37-39, 59].

The hallmark of an anatomic study is standardization. In CT studies of the pelvis, the patient position is often assumed to be uniform [8, 15, 21, 22, 27-29, 31-35, 37, 46, 54, 59, 63], but pelvic positioning can vary greatly, depending on patient size, presence of spine deformities, and hip/lower extremity contractures, all of which can substantially alter measurements of the acetabulum [1, 12, 40, 71]. McKibbin [44] defined the anatomic position of the pelvis as the anterosuperior iliac spines in the same transverse plane and in the same coronal plane as the symphysis pubis. The advantage of the 3-D reconstruction is that surface reconstruction can be reoriented properly, regardless of the patient's positioning during image acquisition [1, 14, 39, 51].

Many authors have emphasized the benefits of 3-D CT in preoperative planning of reconstructive procedures for hip dysplasia [8, 15, 18, 22, 32, 35, 39, 57]; however, controversies remain regarding how dysplastic and typical acetabuli differ in orientation and shape $[5,22,27,46,51$, 54]. In our investigation, nondysplastic and developmentally dysplastic hips were studied using 3-D CT scans, creating a virtual mold or "fill" of the acetabuli. From these fills, parameters of dimension, orientation, and volume were measured and compared.

Specifically, we sought to determine the following: (1) What are the relative size, shape, and orientations of the typically developed nondysplastic hip? (2) How do these variables differ in the developmentally dysplastic hip? (3) Are there version differences between the acetabuli of dysplastic and nondysplastic hips? (4) Are there pairs of variables in which the change in one is always accompanied by a change in the other for both the nondysplastic and dysplastic acetabuli?

\section{Materials and Methods}

We retrospectively reviewed 3-D CT scans of pelvises to measure parameters of dimension (linear and volumetric) and orientation of the acetabulae. The 3-D pelvic reconstructions were first orientated anatomically, regardless of the positioning of the patient during scanning, to standardize the measurements between scans. Representative 3-D volumes of the acetabular space and the femoral head (acetabular fills and femoral head fills, respectively) were constructed, and from these we measured the study variables. Our study was approved by the Research Ethics Board at the Hospital for Sick Children, Toronto, Ontario, Canada. One author (HvB) performed all image orientation and measurements. 
Between March 1988 and October 1995, 198 consecutive pelvic CT scans on patients 10 years or older were performed at the Hospital for Sick Children, Toronto, Canada, and these were retrospectively reviewed. All scans had to include the pubis and both anterosuperior iliac spines (orientational landmarks) so that the pelvis could be reformatted anatomically. Pelvises with an immature triradiate cartilage were excluded. CT scans obtained for the purposes of evaluating hip dysplasia and surgical planning of the same were included only if the origin of the dysplasia was solely developmental and on plain radiograph the hip met criteria for dysplasia by one or more of the following: acetabular indices of more than $20^{\circ}$ [65], Sharp's angles greater than $45^{\circ}$ [60], or center-edge angles less than $20^{\circ}$ for children 13 years old or younger (less than $25^{\circ}$ for subjects older than 13 years of age [73]). Hips that were highly subluxated (center-edge angle $\leq 0^{\circ}$ [73]) or dislocated were excluded. Of the 117 CT scans for hip dysplasia, 20 scans were excluded for patients with neuromuscular hip dysplasia, congenital malformations, or skeletal dysplasias; 28 for hips/pelvises with previous surgical intervention; and 21 for other reasons (not reaching criteria for hip dysplasia, immaturity of the triradiate cartilage, inability to reformat the entire pelvis). Fortyeight scans (34 female and 14 male) met criteria; for those with bilateral hip dysplasia (19 scans), only the left hip was included in the data set.

For the nondysplastic hip group, 55 (32 female and 23 male) of 82 scans met criteria with diagnoses of hip pain without radiologic finding (37), nondisplaced pelvic fractures that did not involve the acetabuli/hip or orientational landmarks (10), osteomyelitis (four), and tumors not affecting one hip and the orientational landmarks (four). Only scans of patients who were developmentally normal, without hip pathology, and mature triradiate cartilages were reviewed. The patient scans were screened to rule out undiagnosed hip dysplasia on plain radiograph, as per the criteria mentioned previously. Twenty-seven scans were excluded for poor quality imaging, morphologic abnormalities involving both hips or the orientational landmarks, or because suitable 3-D CT reconstructions could not be created. For those scans with bilaterally usable hips (19 scans), only the left hip was included in the data set.

The median age for the patients with hip dysplasia was 17.5 years (18.5 years for females, range, 10-40 years; 15 years for males, range, 11-41 years) and for those with nondysplastic hips, median age was 14 years (15 years for females, range, 10-35 years; 13 years for males, range, 10-24 years). The median age for patients with hip dysplasia was skewed by the older age of the postmaturity patients seeking treatment for hip dysplasia at the Hospital for Sick Children. To verify that the distribution of skeletally immature and mature subjects was comparable across

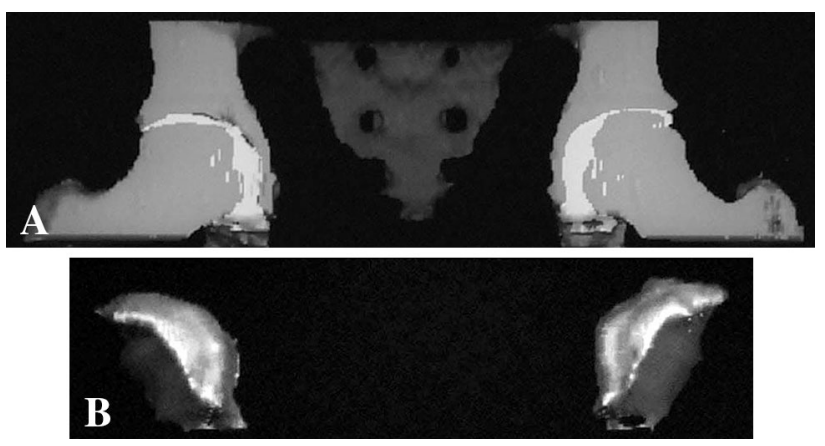

Fig. 1A-B A CT scan shows a subject who has bilateral nondysplastic hips. (A) A reformatted coronal section was taken from the scan through the midacetabulum. The space between the acetabulum and the femoral head is highlighted. The pelvis is positioned anatomically. (B) Three-dimensional acetabular fills were created from the same scan after bony elements were removed. The pelvis is positioned anatomically.

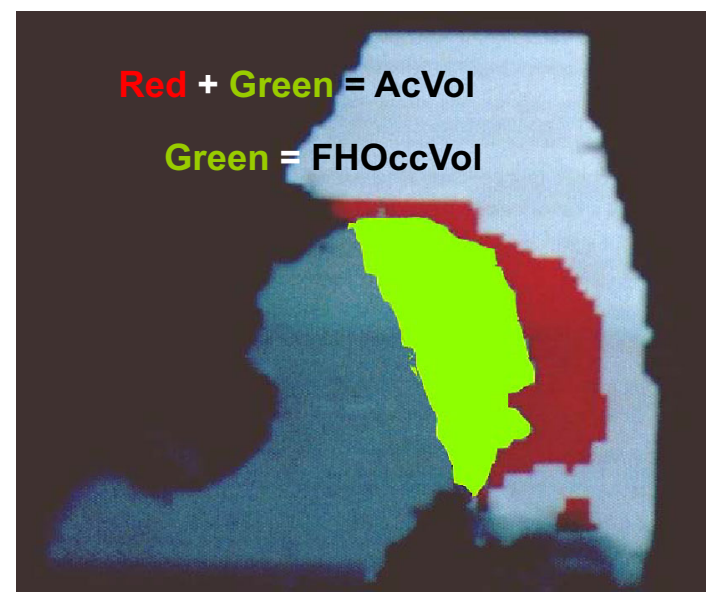

Fig. 2 A coronal cross-section shows a nondysplastic right hip made through the midacetabulum. The entire shaded area (red and green) represents a cross-section of the acetabular fill, the total acetabular volume. The green-shaded area is a cross-section of the volume of the acetabulum occupied by the femoral head. The red-shaded area is the unoccupied acetabular volume, the space between the acetabulum and the femoral head. AcVol = acetabular volume; $\mathrm{FHOccVol}=$ volume of space occupied by the femoral head within the acetabulum.

the sex and diagnosis groups, we divided each group into the "immature" (younger than 14 years old for females, younger than 16 years old for males) and the "mature" categories. Using a chi-square table to compare nondysplastic and dysplastic females, no difference was found in the maturity distribution $(\mathrm{p}=0.862)$. Similarly, there was no difference in the maturity distribution for nondysplastic and dysplastic males $(\mathrm{p}=0.443)$.

The studies were acquired on a General Electric 9800 CT scanner (Milwaukee, WI, USA) with Hilite detectors. Images were attained at 3-mm contiguous intervals of 3-mm thickness [42] or 5-mm intervals for patients older 
Table 1. Description of measured variables

\begin{tabular}{|c|c|c|}
\hline Variable & Acronym & Description \\
\hline Acetabular volume & AcVol & The volume of space occupied within the acetabulum \\
\hline Femoral head volume & FHVol & The volume of space defined by the femoral head \\
\hline Femoral head occupied volume & FHOccVol $\left(\mathrm{mm}^{3}\right)$ & The volume of space within the acetabulum occupied by the femoral head \\
\hline $\begin{array}{l}\text { Percent of the acetabular volume } \\
\text { occupied by the femoral head }\end{array}$ & FHOccVol/AcVol & $\begin{array}{l}\text { Percentage of the available acetabular space (acetabular volume) occupied by } \\
\text { the femoral head }\end{array}$ \\
\hline Length & & Longest coronal distance of acetabulum \\
\hline Width & & Longest distance of the acetabulum in the transverse plane \\
\hline Depth & & $\begin{array}{l}\text { Longest perpendicular distance from the acetabular opening plane to the } \\
\text { medial acetabular wall }\end{array}$ \\
\hline Acetabular anteversion & & $\begin{array}{l}\text { The acute angle between the acetabular opening plane and the sagittal plane } \\
\text { of the pelvis, at the widest level of the acetabulum; a negative value } \\
\text { indicates retroversion }\end{array}$ \\
\hline Torsion 1 & & $\begin{array}{l}\text { The difference between the acetabular anteversion and the version at the } \\
\text { junction of the top and second quarters of the acetabulum; a negative value } \\
\text { indicates retroversion relative to the widest level of the acetabulum }\end{array}$ \\
\hline Torsion 2 & & $\begin{array}{l}\text { The difference between the acetabular anteversion and the version at the } \\
\text { junction of the third and fourth quarters of the acetabulum; a negative } \\
\text { value indicates retroversion relative to the widest level of the acetabulum }\end{array}$ \\
\hline Total torsion & & Summation of Torsion 1 and Torsion 2 \\
\hline Opening plane abduction angle & & $\begin{array}{l}\text { Angle of the acetabular opening plane relative to the transverse plane, with } \\
\text { the acetabulum rotated into a } 0^{\circ} \text { anteversion position }\end{array}$ \\
\hline Roof angle & & $\begin{array}{l}\text { Angle described by the transverse plane and a line from the deepest point of } \\
\text { the acetabulum to the superolateral acetabular corner }\end{array}$ \\
\hline
\end{tabular}

than 16 years as per the radiologists' protocol. The technique used was $120 \mathrm{kVp}$ and 40 to $80 \mathrm{~mA}$, depending on the patient's size. These parameters were chosen to yield a study of sufficient quality yet minimize radiation exposure. Images were stored on magnetic tape or optical disk and transferred to a free-standing computer workstation (Sun Microsystems, Palo Alto, CA, USA). The 3-D volume images and 2-D planar reformatted images were created and analyzed using ISG Allegro multimode rendering software (ISG Technologies [renamed Cedara], Mississauga, Ontario, Canada). Before any measurements, the 3-D pelvic images were reoriented into the anatomic position with both anterosuperior iliac spines in the same transverse plane and in the same coronal plane as the pubis [44, 51]. One author (HvB) performed all image orientations and measurements in a nonblinded manner.

A 3-D representation of the space within the confines of the acetabulum was created by outlining the acetabular walls on each CT slice with the ISG Allegro edge-detection software. The perimeter was closed with a straight line from the anterior to the posterior acetabular lip, thereby defining the cross-sectional area of the acetabulum at that level. The structural sum of these areas resulted in an acetabular fill, a 3-D shape that could be manipulated and measured independently of other structures (Fig. 1A-B). In a similar fashion, a fill representing the femoral head was created. The volume of space each fill described was named the acetabular volume and the femoral head volume, respectively. By overlapping the two fills, the volume of space occupied by the femoral head within the acetabulum, the femoral head occupied volume, could be calculated (Fig. 2). All volumes were measured in $\mathrm{mm}^{3}$. Dividing the femoral head occupied volume by the acetabular volume yielded the percentage of available acetabular space the femoral head occupied.

From the anatomically oriented acetabular fill, six variables were measured (Table 1).

Length of the acetabulum was defined as the longest straight-line distance of the acetabulum in the coronal plane (Fig. 3A).

Width of the acetabulum was defined as the longest straight-line distance of the acetabulum in the transverse plane (Fig. 3B-C). The plane described by the intersection of the length and width lines was named the acetabular opening plane.

Depth of the acetabulum was measured as the longest perpendicular distance from the acetabular opening plane to the medial acetabular wall (Fig. 3A).

Acetabular anteversion, the acute angle between the acetabular opening plane and the sagittal plane of the pelvis, was measured at the widest point of the acetabulum. A negative value denotes retroversion (Fig. 3D-E). 

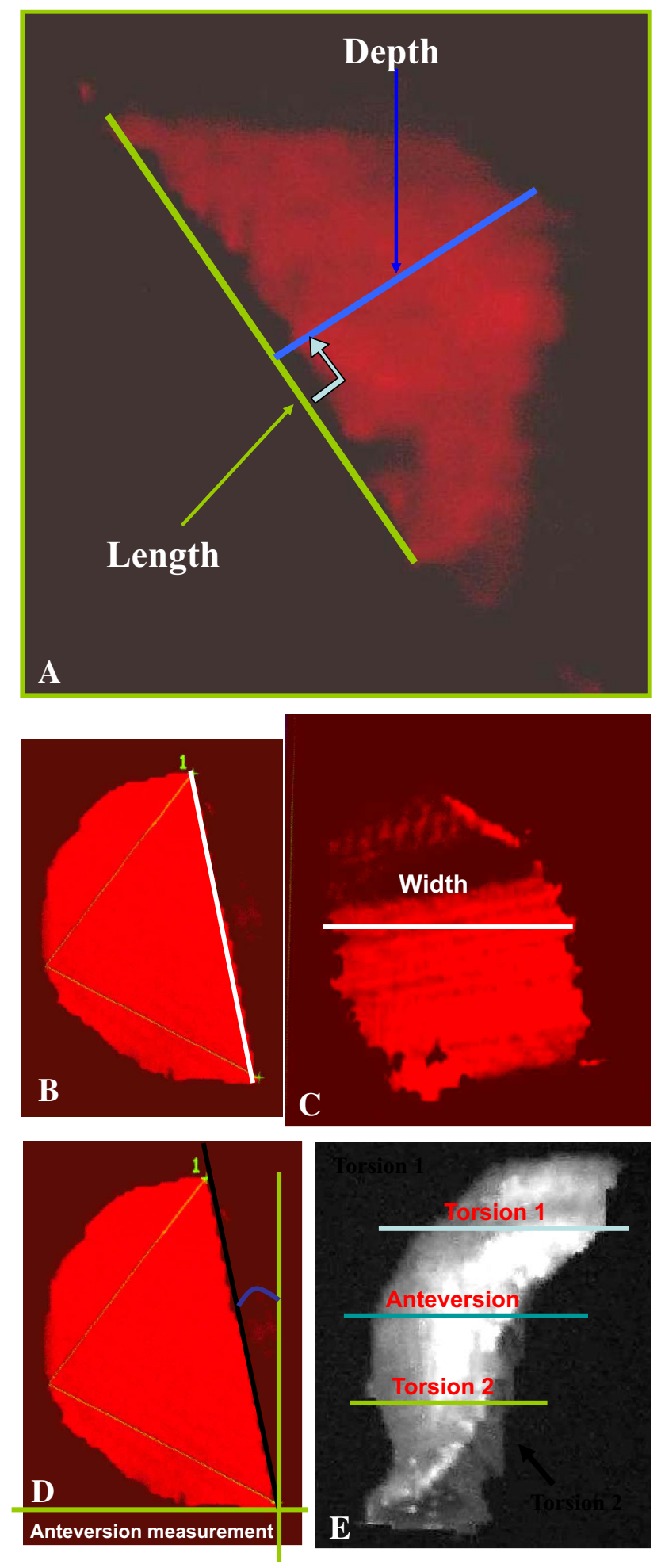

Measurements were stratified according to Tönnis and Heinecke [66].

Torsion 1 is the difference between the acetabular anteversion and the version at the junction of the top and second quarters of the acetabulum (Fig. 3E). A negative
4Fig. 3A-E Reformatted images were acquired from the 3-D CT of a nondysplastic right hip. (A) The acetabular fill rotated into profile (rotating the acetabulum to a $0^{\circ}$ anteversion position) displaying the parameters of length and depth. Length is the longest straight-line distance in the coronal plane. Depth is the greatest perpendicular distance from the acetabular opening plane to the medial acetabular wall. (B) The parameter of width is displayed on a transverse section through an anatomically positioned right acetabulum at the level of the acetabulum's greatest width. (C) A perspective showing a left hip acetabular fill with the opening facing directly toward the viewer. The acetabular width is indicated. The pelvis tilt was corrected to bring the pelvis into the anatomic position. (D) A transverse section is made through the anatomically positioned right acetabulum at its greatest width. The acetabular anteversion is the angle between the sagittal plane of the pelvis and a line connecting the anterior and posterior margins of the acetabulum at this level. (E) A dysplastic left hip acetabular fill-in was rotated into a profile (rotating the acetabulum to a $0^{\circ}$ anteversion position). Anteversion is measured at the widest level of the acetabulum. Torsion 1 is measured at the junction of the first and second quarters, Torsion 2 is measured at the junction of the third and fourth quarters. By comparing figure $\mathbf{E}$, a dysplastic acetabular fill, with Fig. 1B, a nondysplastic acetabular fill, the more elongated and torsioned morphology of the dysplastic acetabulum becomes evident.

value indicates retroversion of the upper acetabulum relative to the widest part of the acetabulum.

Torsion 2 is the difference between the acetabular anteversion and the version at the junction of the third and bottom quarters of the acetabulum (Fig. 3E). A negative value indicates retroversion of the lower acetabulum relative to the widest part of the acetabulum.

Opening plane abduction angle was measured as the acute angle between the acetabular opening plane and the transverse plane of the pelvis. For this measurement, the acetabular fill was viewed in direct profile by rotating the acetabular opening plane until it was perpendicular to the coronal plane $\left(0^{\circ}\right.$ anteversion position) (Fig. $\left.4 \mathrm{~A}\right)$. In the case of an acetabulum that was truly a half sphere, the acetabular position in space could be precisely described by the acetabular anteversion and the opening plane abduction angle.

Roof angle, a measure of the inclination of the acetabular sourcil, was measured as the angle between the horizontal plane and a line connecting the deepest point of the acetabulum to the superolateral corner with the acetabular fill viewed in direct profile by rotating the acetabular opening plane until it was perpendicular to the coronal plane $\left(0^{\circ}\right.$ anteversion position) (Fig. 4B).

Statistical analysis was performed on SAS version 9.4 (SAS Institute Inc, Cary, NC, USA) software. Differences between groups were analyzed using analysis of covariance with means adjusted for age. Fisher's exact test was used to evaluate differences in distributions of acetabular version between nondysplastic and dysplastic groups. Correlations between variables were determined using Pearson correlation with strength of correlation of 0.7 or higher considered "strong." Statistical significance was set at $\mathrm{p} \leq 0.05$. 


\section{Opening Plane}

\section{Abduction Angle}
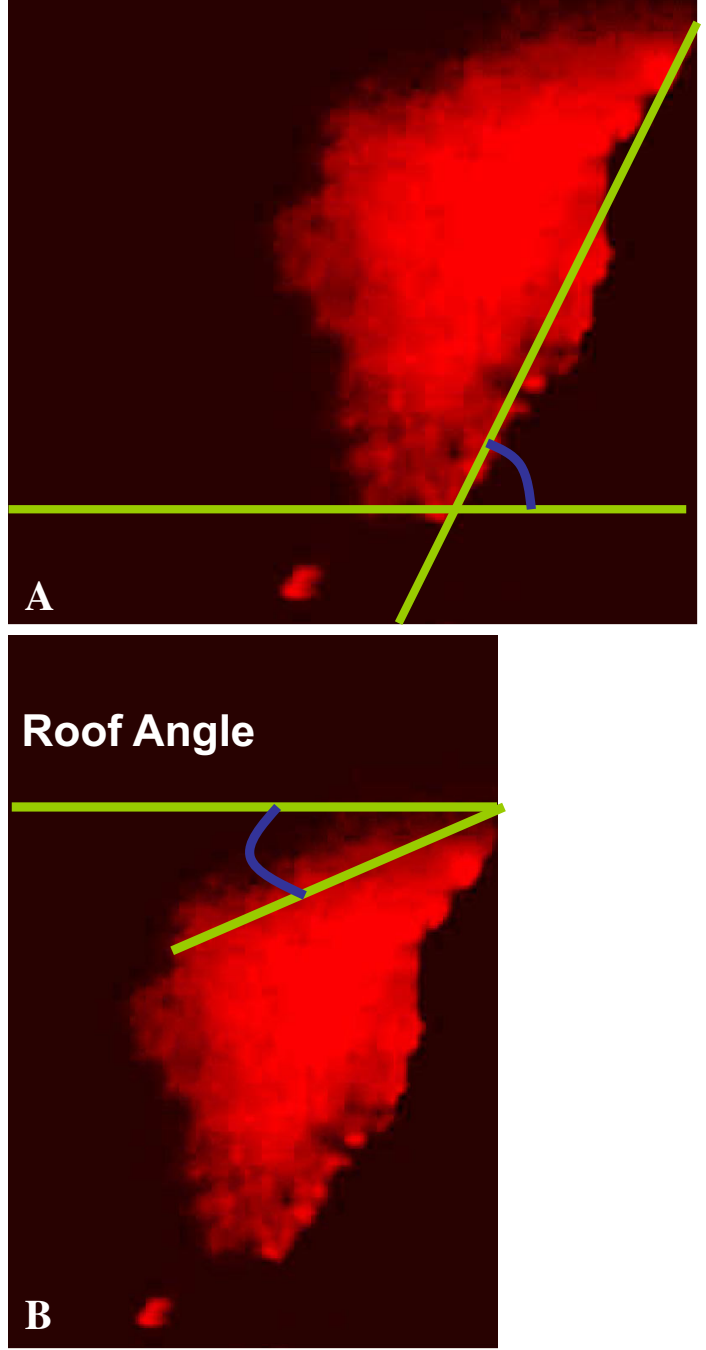

Fig. 4A-B (A) A nondysplastic left hip acetabular fill was rotated into a profile (rotating the acetabulum to a $0^{\circ}$ anteversion position). The opening plane abduction angle is the acute angle between the acetabular opening plane and the transverse plane of the pelvis. (B) The same acetabular fill demonstrates the roof angle. The roof angle is measured as the angle between the transverse plane and a line connecting the superolateral corner and the deepest point of the acetabulum.

\section{Results}

Relative Size, Shape, and Orientations of the Typical Nondysplastic Hip

Nondysplastic acetabuli were nearly hemispherical, with length equal to width, and width twice the depth, for both sexes (Table 2). Male acetabuli were longer $(p=0.006)$ and wider ( $\mathrm{p}=<0.0001$ ) than female acetabula, although there was no difference in depth $(\mathrm{p}=0.141)$. Female subjects had $4^{\circ}(95 \%$ confidence interval [CI], 0.3-7.0) greater acetabular anteversion compared with males $(\mathrm{p}=0.033)$. The version of the upper acetabulum was more retroverted relative to the deepest part of the acetabulum (Torsion 1 ), $3^{\circ} \pm 5.5^{\circ}$ in females $(\mathrm{p}=0.003)$ and $7^{\circ} \pm 11.4^{\circ}$ in males $(\mathrm{p}=0.015)$, but there were no sex differences $(\mathrm{p}=0.209)$. Similarly, the lower acetabulum was relatively anteverted (Torsion 2), $10^{\circ} \pm 6.8^{\circ}$ in females $(\mathrm{p}<0.0001)$ and $14^{\circ} \pm 9.4^{\circ}$ in males $(\mathrm{p}<0.0001)$, without sex differences $(\mathrm{p}=0.242)$. The opening plane abduction angle and roof angle were not different between the sexes $(p=0.123$ and $p=0.135$, respectively). Males had larger acetabular volumes $(\mathrm{p}<$ $0.0001)$, larger femoral head volume $(\mathrm{p}<0.0001)$, and greater femoral head occupied volume $(p=0.0001)$ compared with females. The percentage of acetabular volume that was occupied by the femoral head was not different between female and male subjects $(\mathrm{p}=0.695)$.

We found no difference between each subject's acetabular volume and their calculated hemispherical volume $\left(1 / 2\left[4 / 3 \pi_{\left.\left.\text {radius }^{3}\right]\right)}\right.\right.$ using their depth as the radius in the formula ( $\mathrm{p}=0.715$, paired t-test).

Morphological Differences Between the Nondysplastic and the Dysplastic Hips

Dysplastic hip acetabuli were not hemispherical but were elongated and shallow. For hips with dysplasia, the female acetabuli were longer ( $5 \mathrm{~mm}$; 95\% CI, 1.9-8.0; $\mathrm{p}=0.002$ ), but no difference was seen in males with the numbers available ( $\mathrm{p}=0.061$ ) (Tables 3, 4). For both sexes, the acetabuli were more shallow (females $6.5 \mathrm{~mm}$; 95\% CI, 4.4-8.5; p $<0.0001$; males $5.3 \mathrm{~mm}$; 95\% CI, 2.6-8.1; p = 0.0002) compared with nondysplastic acetabuli. Width was not different between dysplastic and nondysplastic acetabuli for both sexes ( $\mathrm{p}=0.947$ and 0.361 , females and males, respectively). Female hips with dysplastic acetabuli were $5^{\circ}$ more vertically oriented (opening plane abduction angle) than female hips with nondysplastic acetabuli (95\% CI, 1.9-8.1; $\mathrm{p}=0.002)$; there was no such difference between dysplastic and nondysplastic male acetabuli. Female dysplastic acetabuli were more $4^{\circ}$ anteverted (95\% CI, 0.5-6.8; $\mathrm{p}=0.022$ ) than nondysplastic acetabula, but no difference was seen in males $(\mathrm{p}=0.538)$. Roof angles were less horizontal in the dysplastic acetabuli for both sexes $\left(11^{\circ} ; 95 \%\right.$ CI, 7.1-15.2; $\mathrm{p}<0.0001$ for females, $6^{\circ}, 95 \%$ CI, $0.5-11.5 ; \mathrm{p}=0.032$ for males). The dysplastic acetabular volume was $18 \%$ smaller for females ( $p=0.002)$ and $19 \%$ smaller for males $(p=0.0012)$ compared with nondysplastic acetabuli, but femoral head volumes were the same for both sexes ( $p=0.590$ for females, $\mathrm{p}=0.071$ for males). The volume percent of the dysplastic 
Table 2. Sex differences in subjects with nondysplastic hips

\begin{tabular}{|c|c|c|c|c|}
\hline Variable & Females \pm SD & Males $\pm \mathrm{SD}$ & Difference $(95 \%$ confidence interval) $*$ & $\mathrm{p}$ value* \\
\hline Number & 32 & 23 & & \\
\hline $\operatorname{AcVol}\left(\mathrm{mm}^{3}\right)$ & $25,404 \pm 5547$ & $34,255 \pm 6266$ & $9169(6060-12,278)$ & $<0.0001$ \\
\hline FHVol $\left(\mathrm{mm}^{3}\right)$ & $34,221 \pm 7849$ & $47,590 \pm 11,081$ & $14,201(9200-19,202)$ & $<0.0001$ \\
\hline FHOccVol $\left(\mathrm{mm}^{3}\right)$ & $14,646 \pm 3555$ & $19,210 \pm 5589$ & $4846(2429-7264)$ & 0.0001 \\
\hline FHOccVol/AcVol & $57 \% \pm 6 \%$ & $56 \% \pm 12 \%$ & $1 \%(-5$ to 7$)$ & 0.695 \\
\hline Length (mm) & $46.5 \pm 4.6$ & $51.0 \pm 4.9$ & $4.6(1.4-7.9)$ & 0.006 \\
\hline Width (mm) & $46.1 \pm 3.0$ & $51.2 \pm 3.3$ & $5.2(3.2-7.3)$ & $<0.0001$ \\
\hline Depth (mm) & $23.6 \pm 4.0$ & $25.0 \pm 4.3$ & $1.6(-0.6$ to 3.8$)$ & 0.141 \\
\hline Acetabular anteversion & $21.1^{\circ} \pm 5.6^{\circ}$ & $17.2^{\circ} \pm 6.2^{\circ}$ & $3.6^{\circ}(0.3-7.0)$ & 0.033 \\
\hline Torsion 1 & $-3.2^{\circ} \pm-5.5^{\circ}$ & $-6.7^{\circ} \pm 11.4^{\circ}$ & $3.2^{\circ}(-1.8$ to 8.3$)$ & 0.209 \\
\hline Torsion 2 & $10.3^{\circ} \pm 6.8^{\circ}$ & $14.1^{\circ} \pm 9.4^{\circ}$ & $3.4^{\circ}(-2.3$ to 9.1$)$ & 0.242 \\
\hline Total torsion & $13.5^{\circ} \pm 11.7^{\circ}$ & $20.8^{\circ} \pm 20^{\circ}$ & $6.6^{\circ}(-3.8$ to 17.0$)$ & 0.211 \\
\hline Opening plane abduction angle & $55.3^{\circ} \pm 5.2^{\circ}$ & $58.0^{\circ} \pm 6.1^{\circ}$ & $2.6^{\circ}(-0.7$ to 5.9$)$ & 0.126 \\
\hline Roof angle & $15.8^{\circ} \pm 6.1^{\circ}$ & $19.3^{\circ} \pm 6.7^{\circ}$ & $3.3^{\circ}(-7.7$ to 1.1$)$ & 0.135 \\
\hline
\end{tabular}

* Differences calculated from age-adjusted means using analysis of covariance; AcVol = acetabular volume; FHVol = femoral head volume; $\mathrm{FHOccVol}=$ femoral head occupied volume.

Table 3. Comparison of nondysplastic and dysplastic hips in females

\begin{tabular}{|c|c|c|c|c|}
\hline \multirow[t]{2}{*}{ Variable } & \multicolumn{4}{|l|}{ Females } \\
\hline & Nondysplastic \pm SD & Dysplastic \pm SD & Difference* $(95 \%$ confidence interval) & $\mathrm{p}$ value* \\
\hline Number & 32 & 34 & & \\
\hline $\operatorname{AcVol}\left(\mathrm{mm}^{3}\right)$ & $25,404 \pm 5547$ & $22,293 \pm 6229$ & $4733(1804-7661)$ & 0.002 \\
\hline FHVol $\left(\mathrm{mm}^{3}\right)$ & $34,221 \pm 7849$ & $37,178 \pm 11,310$ & $1284(-3426$ to 5994$)$ & 0.590 \\
\hline FHOccVol $\left(\mathrm{mm}^{3}\right)$ & $14,646 \pm 3555$ & $8319 \pm 4340$ & $7763(5486-10,040)$ & $<0.0001$ \\
\hline $\mathrm{FHOccVol} / \mathrm{AcVol}$ & $57 \% \pm 6 \%$ & $35 \% \pm 13 \%$ & $25 \%(20-31)$ & $<0.0001$ \\
\hline Length (mm) & $46.5 \pm 4.6$ & $52.4 \pm 6.2$ & $5.0(1.9-8.0)$ & 0.002 \\
\hline Width (mm) & $46.1 \pm 3.0$ & $47.1 \pm 4.7$ & $0.1(-1.8$ to 2.0$)$ & 0.947 \\
\hline Depth (mm) & $23.6 \pm 4.0$ & $18.7 \pm 4.9$ & $6.5(4.4-8.5)$ & $<0.0001$ \\
\hline Acetabular anteversion & $21.1^{\circ} \pm 5.6^{\circ}$ & $26.1^{\circ} \pm 6.4^{\circ}$ & $3.7^{\circ}(0.5-6.8)$ & 0.022 \\
\hline Torsion 1 & $-3.2^{\circ} \pm 5.5^{\circ}$ & $-11.9^{\circ} \pm 8.6^{\circ}$ & $10.2^{\circ}(5.5-15.0)$ & $<0.0001$ \\
\hline Torsion 2 & $10.3^{\circ} \pm 6.8^{\circ}$ & $19.1^{\circ} \pm 11.2^{\circ}$ & $10.7^{\circ}(5.4-16.1)$ & 0.0001 \\
\hline Total torsion & $13.5^{\circ} \pm 11.7^{\circ}$ & $31.0^{\circ} \pm 19.2^{\circ}$ & $20.9^{\circ}(11.2-30.7)$ & $<0.0001$ \\
\hline Opening plane abduction angle & $55.3^{\circ} \pm 5.2^{\circ}$ & $59.5^{\circ} \pm 6.9^{\circ}$ & $5.0^{\circ}(1.9-8.1)$ & 0.002 \\
\hline Roof angle & $15.8^{\circ} \pm 6.1^{\circ}$ & $26.2^{\circ} \pm 10.2^{\circ}$ & $11.2^{\circ}(7.1-15.2)$ & $<0.0001$ \\
\hline
\end{tabular}

* Differences calculated from age-adjusted means using analysis of covariance; AcVol = acetabular volume; FHVol = femoral head volume; $\mathrm{FHOccVol}=$ femoral head occupied volume .

acetabulum occupied by the femoral head was only $35 \% \pm 13 \%$ for females, a decrease of $25 \%$ (95\% CI, 20-31; $\mathrm{p}<0.0001)$, and $36 \% \pm 17 \%$, a decrease of $23 \%(95 \% \mathrm{CI}$, $15-30 ; \mathrm{p}<0.0001)$ for males compared with nondysplastic hips, suggesting subluxation.

\section{Differences in Acetabular Version}

Female dysplastic acetabuli were $3.7^{\circ}$ more anteverted than nondysplastic acetabuli (95\% CI, 0.5-6.8; $\mathrm{p}=0.022$ ), whereas there was no difference for males $(\mathrm{p}=0.538)$. The classification of Tönnis and Heinecke [66] for acetabular version was modified so that acetabuli were stratified into typical version (Grade $1,15^{\circ}-20^{\circ}$ ), relative retroversion (Grade -3 and -2 combined, $<14^{\circ}$ anteversion), or relative excessive anteversion (Grade 2 and Grade 3 combined, $>21^{\circ}$ anteversion) so as to decrease the number of cells with low counts. Using Fisher's exact test, a higher proportion of anteverted dysplastic acetabuli, in both males and females, was found compared with nondysplastic acetabuli ( $p=0.002$ for females, $p=0.061$ for 
Table 4. Comparison of nondysplastic and dysplastic hips in males

\begin{tabular}{|c|c|c|c|c|}
\hline \multirow[t]{2}{*}{ Variable } & \multicolumn{4}{|l|}{ Males } \\
\hline & Nondysplastic \pm SD & Dysplastic \pm SD & Difference* $^{*}(95 \%$ confidence interval) & $\mathrm{p}$ value* \\
\hline Number & 23 & 14 & & \\
\hline $\operatorname{AcVol}\left(\mathrm{mm}^{3}\right)$ & $34,255 \pm 6266$ & $29,164 \pm 6581$ & $6602(2669-10,353)$ & 0.0012 \\
\hline FHVol $\left(\mathrm{mm}^{3}\right)$ & $47,590 \pm 11,081$ & $45,713 \pm 14,038$ & $5831(-497$ to 12,158$)$ & 0.071 \\
\hline FHOccVol $\left(\mathrm{mm}^{3}\right)$ & $19,210 \pm 5589$ & $11,306 \pm 6762$ & $9243(6184-12,301)$ & $<0.0001$ \\
\hline $\mathrm{FHOccVol} / \mathrm{AcVol}$ & $56 \% \pm 12 \%$ & $36 \% \pm 17 \%$ & $23 \%(15-30)$ & $<0.0001$ \\
\hline Length (mm) & $51.0 \pm 4.9$ & $55.8 \pm 9.7$ & $3.9(-0.2$ to 8.1$)$ & 0.061 \\
\hline Width (mm) & $51.2 \pm 3.3$ & $50.9 \pm 4.4$ & $1.2(-1.4$ to 3.7$)$ & 0.361 \\
\hline Depth (mm) & $25.0 \pm 4.3$ & $21.1 \pm 4.8$ & $5.3(2.6-8.1)$ & 0.0002 \\
\hline Acetabular anteversion & $17.2^{\circ} \pm 6.2^{\circ}$ & $19.7^{\circ} \pm 7.4^{\circ}$ & $1.3^{\circ}(-2.8$ to 5.4$)$ & 0.538 \\
\hline Torsion 1 & $-6.7^{\circ} \pm 11.4^{\circ}$ & $-12.4^{\circ} \pm 14.0^{\circ}$ & $7.0^{\circ}(0.6-13.4)$ & 0.032 \\
\hline Torsion 2 & $14.1^{\circ} \pm 9.4^{\circ}$ & $18.8^{\circ} \pm 17.5^{\circ}$ & $6.5^{\circ}(-0.7$ to 13.8$)$ & 0.075 \\
\hline Total torsion & $20.8^{\circ} \pm 19.9^{\circ}$ & $31.1^{\circ} \pm 31.4^{\circ}$ & $13.6^{\circ}(0.4-26.7)$ & 0.043 \\
\hline Opening plane abduction angle & $58.0^{\circ} \pm 6.1^{\circ}$ & $57.0^{\circ} \pm 5.7^{\circ}$ & $0.3^{\circ}(-3.9$ to 4.5$)$ & 0.888 \\
\hline Roof angle & $19.3^{\circ} \pm 6.7^{\circ}$ & $24.6^{\circ} \pm 6.5^{\circ}$ & $6.0^{\circ}(0.5-11.5)$ & 0.032 \\
\hline
\end{tabular}

* Differences calculated from age-adjusted means using analysis of covariance; AcVol = acetabular volume; FHVol = femoral head volume; $\mathrm{FHOccVol}=$ femoral head occupied volume.

Table 5. Hips by Tönnis grade of anteversion

\begin{tabular}{lcccc}
\hline Tönnis grade of anteversion & Nondysplastic female & Dysplastic female & Nondysplastic male & Dysplastic male \\
\hline Grade $-3\left(<10^{\circ}\right)$ and Grade $-2\left(10^{\circ}-14^{\circ}\right)$ & 4 & 2 & 8 & 3 \\
Grade $1\left(15^{\circ}-20^{\circ}\right)$ & 12 & 4 & 12 & 4 \\
Grade 2 $\left(21^{\circ}-25^{\circ}\right)$ and Grade $3\left(>25^{\circ}\right)$ & 16 & 28 & 3 & 7 \\
Total hips & 32 & 34 & 23 & 14 \\
\hline
\end{tabular}

males) (Table 5). Torsion 1 was more retroverted in dysplastic acetabuli compared with nondysplastic acetabuli for both sexes $\left(10^{\circ} ; 95 \% \mathrm{CI}, 5.5-15.0 ; \mathrm{p}<0.0001\right.$ for females, $7^{\circ} ; 95 \% \mathrm{CI}, 6-13.4 ; \mathrm{p}=0.032$ for males). Torsion 2 was more anteverted in female dysplastic acetabuli $\left(11^{\circ} ; 95 \%\right.$ CI, 5.4-16.1; $\mathrm{p}=0.0001)$; there was no difference seen for males $(\mathrm{p}=0.075)$. Total torsion (summation of Torsion 1 and Torsion 2) was greater for dysplastic acetabuli than nondysplastic, both for females $\left(20.9^{\circ}\right.$; $95 \%$ CI, 11.2-30.7; $\mathrm{p}<0.0001)$ and males $\left(13.6^{\circ} ; 95 \%\right.$ CI, 0.4-26.7; $\mathrm{p}=0.043)$.

\section{Correlation of Hip Variables}

Pearson product-moment correlation coefficients were calculated for all possible pairings of variables, both for nondysplastic and dysplastic hips, with strength of correlation of 0.7 or higher considered "strong" (Tables 6,7$)$. In the nondysplastic hips, the acetabular volume was correlated to width $(\mathrm{r}=0.79, \mathrm{p}<0.0001)$, whereas in the dysplastic hips, it was correlated to both width $(r=0.72, p<0.0001)$ and depth $(r=0.74, p<0.0001)$, indicating that changes in acetabular depth in the dysplastic hip were linked to decreases in acetabular volume. In both nondysplastic and dysplastic hips, the acetabular volume correlated with femoral head volume $(\mathrm{r}=0.85, \mathrm{p}<0.001$ and $\mathrm{r}=0.71$, $\mathrm{p}<0.0001$, respectively) and the space within the acetabulum occupied by the femoral head ( $\mathrm{r}=0.86, \mathrm{p}<0.0001$, and $\mathrm{r}=0.84, \mathrm{p}<0.0001$, respectively). As Torsion 1 became more retroverted Torsion 2 became more anteverted in both nondysplastic and dysplastic acetabuli $(\mathrm{r}=0.81$, $\mathrm{p}<0.0001$, and $\mathrm{r}=0.93, \mathrm{p}<0.0001$, respectively).

\section{Discussion}

In our report, 103 3-D CT pelvis reconstructions were repositioned anatomically, allowing for consistent and comparable measurements of orientation and dimension parameters, to evaluate the differences between nondysplastic and dysplastic hips.

We note several limitations of this study. First, all measurements were made by only one investigator (HvB). Others 
Table 6. Correlation of variables, nondysplastic

\begin{tabular}{llccc}
\hline Variable & Correlated variable & Pearson correlation coefficient $(\mathrm{r})$ & $95 \%$ confidence interval & $\mathrm{p}$ value \\
\hline AcVol & Width & 0.79 & $0.65-0.87$ & $<0.0001$ \\
& FHVol & 0.85 & $0.75-0.91$ & $<0.0001$ \\
& FHOccVol & 0.86 & $0.76-0.91$ & $<0.0001$ \\
FHVol & Width & 0.79 & $0.66-0.87$ & $<0.0001$ \\
& FHOccVol & 0.74 & $0.59-0.84$ & $<0.0001$ \\
Torsion 1 & Torsion 2 & -0.81 & -0.88 to -0.69 & $<0.0001$ \\
Roof angle & Opening plane abduction angle & -0.72 & -0.82 to -0.55 & $<0.0001$ \\
\hline
\end{tabular}

$\mathrm{AcVol}=$ acetabular volume; FHVol = femoral head volume; FHOccVol = femoral head occupied volume.

Table 7. Correlation of variables, dysplastic

\begin{tabular}{lllll}
\hline Variable & Correlated variable & Pearson correlation coefficient $(\mathrm{r})$ & $95 \%$ confidence interval & $\mathrm{p}$ value \\
\hline AcVol & Width & 0.72 & $0.54-0.83$ & $<0.0001$ \\
& Depth & 0.74 & $0.58-0.85$ & $<0.0001$ \\
& FHVol & 0.71 & $0.53-0.83$ & $<0.0001$ \\
& FHOccVol & 0.84 & $0.72-0.91$ & $<0.0001$ \\
FHOccVol & Depth & 0.73 & $0.56-0.84$ & $<0.0001$ \\
& FHOccVol/AcVol & 0.90 & $0.82-0.94$ & $<0.0001$ \\
Torsion 1 & Torsion 2 & -0.93 & -0.96 to -0.87 & $<0.0001$ \\
\hline
\end{tabular}

AcVol = acetabular volume; FHVol = femoral head volume; FHOccVol = femoral head occupied volume.

have found satisfactory reproducibility for acetabular measures on 2-D CT scans of hips, including a $95 \%$ intraobserver reproducibility within $3.5^{\circ}$ for acetabular anteversion [34], intraobserver intraclass coefficients (ICC) ranging from 0.79 and 0.87 for variables including acetabular anteversion [29] and mean interobserver ICC of 0.96 for measures including acetabular anteversion for normal and dysplastic hips [11]. The images were acquired and processed with older technology with thicker slices than achievable with modern helical scanners. We believe that the precision of the data was suitable enough to detect differences between the nondysplastic and dysplastic acetabuli. We did not have the ability to correlate symptoms with the differences in measured parameters. Our goal was to describe how dysplastic and nondysplastic acetabuli differed rather than to correlate morphologic changes to symptoms. The male cohort of the study was small. Some parameters differed significantly between nondysplastic and dysplastic hips in females but were underpowered to make these comparisons in males. Another possible limitation of our study is that the CT scans we reviewed had all been performed with the patient in the supine position rather than upright and weightbearing. Only the femoral head occupied volume would be potentially affected by loading or unloading the joint.

The nondysplastic acetabulum is a nearly perfect hemisphere with dimensions of the coronal plane (length) and transverse plane (width) essentially equal and twice the acetabular depth [24, 46, 51]. The acetabulum is relatively retroverted superiorly and relatively anteverted inferiorly compared with the deepest part of the acetabulum, a finding described for dysplastic acetabuli [13, 25, 37, 67], but not often reported as occurring in nondysplastic acetabuli [58]. The male acetabulum is $27 \%$ larger than the female, and the male femoral head is $30 \%$ greater than the female; despite that, the femoral head occupies the same percentage of acetabular space for both females and males. Other than a $4^{\circ}$ difference in anteversion (discussed subsequently), there are no other acetabular orientational differences between the sexes.

Developmentally dysplastic acetabuli are not merely deficient in a single plane or dimension, but are globally deficient both in shape and orientation. Dysplasia manifests in "acetabular elongation," where the width remains comparable to the nondysplastic acetabulum, but length is increased and depth decreased [37]. Whereas a nondysplastic acetabulum could be conceptualized as half of a tennis ball, the dysplastic acetabulum is much like taking that half ball, stretching it lengthwise, and twisting it along the axis, keeping the width constant. The subluxated femoral head lies superiorly and laterally in the elongated and retroverted part of the acetabulum. This region becomes progressively shallower as the acetabulum increases in 
length and a lack of superior coverage results. Presumably, the high-riding femoral head does not provide enough pressure to the midacetabulum, which subsequently does not remodel to sufficient depth with growth. The small decrease in acetabular volume indicates that volume lost resulting from a shallower acetabulum is somewhat balanced by the coronal expansion of the dysplastic acetabulum. Femoral head sizes of the age-adjusted groups were essentially the same in our study. As determined by the acetabular width, the femoral heads were appropriately sized for the reduction into the dysplastic acetabuli [59]. We found the femoral head occupied 53\% less volume of the dysplastic acetabulum compared with the nondysplastic hips in females and $48 \%$ less in males. The opening plane abduction angle, analogous to the hip abduction angle [35] but adjusted for the acetabular anteversion, was only mildly increased in dysplastic female acetabuli, reflecting the findings of others $[46,51]$; there was no difference measured for males in our study. In our results, the roof angle was $11^{\circ}$ less horizontal in the dysplastic female hips and $6^{\circ}$ less in males, a finding similar to that of Ito et al. [27]. These relatively small changes in the opening plane abduction and roof angles of dysplastic acetabuli indicate how sensitive femoral head coverage and stability are to changes in the superior acetabulum.

We found that females with nondypslastic acetabuli were $4^{\circ}$ more anteverted than males, similar to findings by Anda et al. $\left(3^{\circ}\right)$ [2] and Tallroth and Lepistö (5 $5^{\circ}$ [63]; most other studies did not specify anteversion by sex $[4,27,29$, 30]. Acetabular anteversion for both sexes was no different with dysplastic and nondysplastic acetabuli $[3,4,13,29$, $33,46,48,51,56]$. The superior portion of the acetabulum (Torsion 1) was retroverted and the inferior portion (Torsion 2) was anteverted relative to the widest aspect of the acetabulum. The absolute acetabular torsion (Torsions 1 and 2 combined) was $14^{\circ}$ in females and $21^{\circ}$ in males in nondysplastic acetabuli, and was increased in dysplastic acetabuli, $31^{\circ}$ for both sexes, from superoposterior to inferoanterior. These findings may represent the remodeling pressure of the femoral head on the posterosuperior acetabular rim $[13,37]$ and pressure from an aberrant iliopsoas tendon on the inferior dysplastic acetabulum [25, 37, 67].

There are conflicting data on whether a greater percentage of dysplastic acetabuli are retroverted on CT studies [4, 9, 27-29, 33, 34, 46, 51, 58]. When stratifying acetabular anteversion by Tönnis grade, we found no disproportionate percentage of retroverted acetabuli (Tönnis Grades -3 and -2) among the dysplastic hips compared with the nondysplastic hips (Table 5). Some authors have suggested measuring acetabular version more superiorly on CT scans to coincide with the crossover sign seen on radiographs of retroverted acetabuli [34, 41, 58]. Torsion 1 was more retroverted in the dysplastic acetabuli, but the version measurement at the point of greatest acetabular width is the most meaningful, describing the acetabular orientation at a level where the femoral head should be most deeply contained. Because the goal of reconstructive osteotomies is to place the femoral head as deeply as possible within the acetabulum, using the superior aspect of the acetabulum to determine version correction will result in too much anteversion of the central (load-bearing) aspect of the acetabulum. Also, after reconstruction, the most superior aspect of the acetabulum should be much less weightbearing.

We were unable to find relevant literature describing correlations between different acetabular variables. It is intriguing that the acetabular volume is most closely correlated to the acetabular width, and that in the dysplastic acetabulum, the loss of acetabular depth is directly correlated to loss of acetabular volume, whereas the change in acetabular length is not. Dysplasia causes the strong relationship between two orientation variables, roof angle and opening plane abduction angle, seen in the nondysplastic hips, to become unlinked.

It is well understood that dysplasia of the acetabulum can be compensated for but not restored to normal. Finite element analysis has shown that reconstructive procedures such as the Bernese periacetabular osteotomy (PAO) can increase joint contact area and decrease joint contact pressures $[6,36]$ but cannot reach predicted normal values, probably because of the irregular shape of dysplastic hips [20, 74]. Medium-term results (5.5 years to 15 years) after PAO show a rate of conversion to THA between $7 \%$ and $15 \%[19,36,43,68]$. Steppacher et al. reported on a series of patients with at least 19 years followup after PAO and found that of 32 patients without preoperative signs of arthritis, six (19\%) were converted to THA [62]. We believe that the true pathological anatomy of the dysplastic hip prevents normalization of the joint by reconstructive means as a result of its elongated and shallow deformity. Although reconstructive measures may reverse symptoms and disability by stabilizing the hip to reduce shear force on the acetabular roof, and possibly slow the progression of OA, it must be recognized that they do not produce an anatomically normal hip. We suggest that one of the goals of treatment should be to increase the volume of the femoral head contained within the acetabulum, thereby increasing the load-bearing surface of the joint [26, 45]. In the typical dysplastic hip, a redirectional osteotomy of the acetabulum should rotate the superolateral rim directly inferiorly around an axis defined by the greatest acetabular width. The acetabular anteversion should be decreased little, if at all. Because a mature dysplastic acetabulum cannot be normalized, more emphasis should be placed on identifying and treating dysplastic hips earlier in hopes that they will sufficiently remodel to ensure longer survivorship [64]. 
Acknowledgments We thank John Gaughan MS, PhD, MBA, of Temple University, Philadelphia, PA, USA, for providing statistical support, and Ms Carolyn Hendrix of the Shriners Hospital for Children, Philadelphia, PA, USA, for her assistance in arranging and organizing this article, and for assisting the coauthors.

\section{References}

1. Abel MF, Sutherland DH, Wenger DR, Mubarak SJ. Evaluation of CT scans and 3-D reformatted images for quantitative assessment of the hip. J Pediatr Orthop. 1994;14:48-53.

2. Anda S, Svenningsen S, Dale LG, Benum P. The acetabular sector angle of the adult hip determined by computed tomography. Acta Radiol Diagn (Stockh). 1986;27:443-447.

3. Anda S, Terjesen T, Kvistad KA. Computed tomography measurements of the acetabulum in adult dysplastic hips: which level is appropriate? Skeletal Radiol. 1991;20:267-271.

4. Anda S, Terjesen T, Kvistad KA, Svenningsen S. Acetabular angles and femoral anteversion in dysplastic hips in adults: CT investigation. J Comput Assist Tomogr. 1991;15:115-120.

5. Argenson JN, Ryembault E, Flecher X, Brassart N, Parratte S, Aubaniac JM. Three-dimensional anatomy of the hip in osteoarthritis after developmental dysplasia. J Bone Joint Surg Br. 2005;87:1192-1196.

6. Armiger RS, Armand M, Tallroth K, Lepisto J, Mears SC. Threedimensional mechanical evaluation of joint contact pressure in 12 periacetabular osteotomy patients with 10-year follow-up. Acta Orthop. 2009;80:155-161.

7. Aronson J. Osteoarthritis of the young adult hip: etiology and treatment. Instr Course Lect. 1986;35:119-128.

8. Azuma $\mathrm{H}$, Taneda $\mathrm{H}$, Igarashi $\mathrm{H}$. Evaluation of acetabular coverage: three-dimensional CT imaging and modified pelvic inlet view. J Pediatr Orthop. 1991;11:765-769.

9. Browning WH, Rosenkrantz H, Tarquinio T. Computed tomography in congenital hip dislocation. The role of acetabular anteversion. J Bone Joint Surg Am. 1982;64:27-31.

10. Cooperman DR, Wallensten R, Stulberg SD. Acetabular dysplasia in the adult. Clin Orthop Relat Res. 1983;175:79-85.

11. Dandachli W, Kannan V, Richards R, Shah Z, Hall-Craggs M, Witt J. Analysis of cover of the femoral head in normal and dysplastic hips: new CT-based technique. J Bone Joint Surg Br. 2008;90:1428-1434.

12. Eddine TA, Migaud H, Chantelot C, Cotten A, Fontaine C, Duquennoy A. Variations of pelvic anteversion in the lying and standing positions: analysis of 24 control subjects and implications for CT measurement of position of a prosthetic cup. Surg Radiol Anat. 2001;23:105-110.

13. Edelson JG, Hirsch M, Weinberg H, Attar D, Barmeir E. Congenital dislocation of the hip and computerised axial tomography. J Bone Joint Surg Br. 1984;66:472-478.

14. Ferran JL, A. Dimeglio, N. Lebouco, A. Couture, V. De Rosa. Three-dimensional computed tomography of the infantile hip. $J$ Pediatr Orthop B. 1994;3:131-134.

15. Frick SL, Kim SS, Wenger DR. Pre- and postoperative threedimensional computed tomography analysis of triple innominate osteotomy for hip dysplasia. J Pediatr Orthop. 2000;20:116-123.

16. Ganz R, Klaue K, Vinh TS, Mast JW. A new periacetabular osteotomy for the treatment of hip dysplasias. Technique and preliminary results. Clin Orthop Relat Res. 1988;232:26-36.

17. Ganz R, Leunig M, Leunig-Ganz K, Harris WH. The etiology of osteoarthritis of the hip: an integrated mechanical concept. Clin Orthop Relat Res. 2008;466:264-272.

18. Garbuz DS, Masri BA, Haddad F, Duncan CP. Clinical and radiographic assessment of the young adult with symptomatic hip dysplasia. Clin Orthop Relat Res. 2004;418:18-22.
19. Garras DN, Crowder TT, Olson SA. Medium-term results of the Bernese periacetabular osteotomy in the treatment of symptomatic developmental dysplasia of the hip. J Bone Joint Surg Br. 2007;89:721-724.

20. Genda E, Iwasaki N, Li G, MacWilliams BA, Barrance PJ, Chao EY. Normal hip joint contact pressure distribution in single-leg standing - effect of gender and anatomic parameters. J Biomech. 2001;34:895-905.

21. Gugenheim JJ, Gerson LP, Sadler C, Tullos HS. Pathologic morphology of the acetabulum in paralytic and congenital hip instability. J Pediatr Orthop. 1982;2:397-400.

22. Haddad FS, Garbuz DS, Duncan CP, Janzen DL, Munk PL. CT evaluation of periacetabular osteotomies. J Bone Joint Surg Br. 2000;82:526-531.

23. Harris WH. Etiology of osteoarthritis of the hip. Clin Orthop Relat Res. 1986;213:20-33.

24. Hauser DL, Fox JC, Sukin D, Mudge B, Coutts RD. Anatomic variation of structural properties of periacetabular bone as a function of age. A quantitative computed tomography study. $J$ Arthroplasty. 1997;12:804-811.

25. Hernandez RJ, Poznanski AK. CT evaluation of pediatric hip disorders. Orthop Clin North Am. 1985;16:513-541.

26. Hipp JA, Sugano N, Millis MB, Murphy SB. Planning acetabular redirection osteotomies based on joint contact pressures. Clin Orthop Relat Res. 1999;364:134-143.

27. Ito H, Matsuno T, Hirayama T, Tanino H, Yamanaka Y, Minami A. Three-dimensional computed tomography analysis of nonosteoarthritic adult acetabular dysplasia. Skeletal Radiol. 2009;38:131-139.

28. Jacobsen S, Romer L, Soballe K. Degeneration in dysplastic hips. A computer tomography study. Skeletal Radiol. 2005;34:778784 .

29. Jacobsen S, Romer L, Soballe K. The other hip in unilateral hip dysplasia. Clin Orthop Relat Res. 2006;446:239-246.

30. Jacquemier M, Jouve JL, Bollini G, Panuel M, Migliani R. Acetabular anteversion in children. $J$ Pediatr Orthop. 1992;12:373-375.

31. Kim HT, Wenger DR. Location of acetabular deficiency and associated hip dislocation in neuromuscular hip dysplasia: threedimensional computed tomographic analysis. J Pediatr Orthop. 1997; 17:143-151.

32. Kim HT, Wenger DR. The morphology of residual acetabular deficiency in childhood hip dysplasia: three-dimensional computed tomographic analysis. J Pediatr Orthop. 1997;17:637-647.

33. Kim SS, Frick SL, Wenger DR. Anteversion of the acetabulum in developmental dysplasia of the hip: analysis with computed tomography. J Pediatr Orthop. 1999;19:438-442.

34. Kim WY, Hutchinson CE, Andrew JG, Allen PD. The relationship between acetabular retroversion and osteoarthritis of the hip. J Bone Joint Surg Br. 2006;88:727-729.

35. Klaue K, Wallin A, Ganz R. CT evaluation of coverage and congruency of the hip prior to osteotomy. Clin Orthop Relat Res. 1988;232:15-25.

36. Kralj M, Mavcic B, Antolic V, Iglic A, Kralj-Iglic V. The Bernese periacetabular osteotomy: clinical, radiographic and mechanical 7-15-year follow-up of 26 hips. Acta Orthop. 2005;76:833-840.

37. Lafferty CM, Sartoris DJ, Tyson R, Resnick D, Kursunoglu S, Pate D, Sutherland D. Acetabular alterations in untreated congenital dysplasia of the hip: computed tomography with multiplanar re-formation and three-dimensional analysis. $J$ Comput Assist Tomogr. 1986;10:84-91.

38. Lang P, Genant HK, Steiger P, Lindquist T, Moore S, Skinner SR. Three-dimensional digital displays in congenital dislocation of the hip: preliminary experience. $J$ Pediatr Orthop. 1989;9:532-537. 
39. Lee DY, Choi IH, Lee CK, Cho TJ. Assessment of complex hip deformity using three-dimensional CT image. J Pediatr Orthop. 1991;11:13-19.

40. Lembeck B, Mueller O, Reize P, Wuelker N. Pelvic tilt makes acetabular cup navigation inaccurate. Acta Orthop. 2005;76:517523.

41. Li PL, Ganz R. Morphologic features of congenital acetabular dysplasia: one in six is retroverted. Clin Orthop Relat Res. 2003;416:245-253.

42. Magid D. Computed tomographic imaging of the musculoskeletal system. Current status. Radiol Clin North Am. 1994;32:255-274.

43. Matheney T, Kim YJ, Zurakowski D, Matero C, Millis M. Intermediate to long-term results following the Bernese periacetabular osteotomy and predictors of clinical outcome. $J$ Bone Joint Surg Am. 2009;91:2113-2123.

44. McKibbin B. Anatomical factors in the stability of the hip joint in the newborn. J Bone Joint Surg Br. 1970;52:148-159.

45. Mechlenburg I, Nyengaard JR, Romer L, Soballe K. Changes in load-bearing area after Ganz periacetabular osteotomy evaluated by multislice CT scanning and stereology. Acta Orthop Scand. 2004;75:147-153.

46. Millis MB, Murphy SB. Use of computed tomographic reconstruction in planning osteotomies of the hip. Clin Orthop Relat Res. 1992;274:154-159.

47. Millis MB, Murphy SB, Poss R. Osteotomies about the hip for the prevention and treatment of osteoarthrosis. J Bone Joint Surg Am. 1995;77:626-647.

48. Millis MB, Poss R, Murphy SB. Osteotomies of the hip in the prevention and treatment of osteoarthritis. Instr Course Lect. 1992;41:145-154.

49. Murphy S, Deshmukh R. Periacetabular osteotomy: preoperative radiographic predictors of outcome. Clin Orthop Relat Res. 2002;405:168-174.

50. Murphy SB, Ganz R, Muller ME. The prognosis in untreated dysplasia of the hip. A study of radiographic factors that predict the outcome. J Bone Joint Surg Am. 1995;77:985-989.

51. Murphy SB, Kijewski PK, Millis MB, Harless A. Acetabular dysplasia in the adolescent and young adult. Clin Orthop Relat Res. 1990;261:214-223.

52. Murphy SB, Millis MB, Hall JE. Surgical correction of acetabular dysplasia in the adult. A Boston experience. Clin Orthop Relat Res. 1999;363:38-44.

53. Nakamura S, Ninomiya S, Takatori Y, Morimoto S, Umeyama T. Long-term outcome of rotational acetabular osteotomy: 145 hips followed for 10-23 years. Acta Orthop Scand. 1998;69:259-265.

54. Nakamura S, Yorikawa J, Otsuka K, Takeshita K, Harasawa A, Matsushita T. Evaluation of acetabular dysplasia using a top view of the hip on three-dimensional CT. J Orthop Sci. 2000;5:533-539.

55. Ninomiya S. Rotational acetabular osteotomy for the severely dysplastic hip in the adolescent and adult. Clin Orthop Relat Res. 1989;247:127-137.

56. Ogata S, Moriya H, Tsuchiya K, Akita T, Kamegaya M, Someya M. Acetabular cover in congenital dislocation of the hip. $J$ Bone Joint Surg Br. 1990;72:190-196.
57. Peterson HA, Klassen RA, McLeod RA, Hoffman AD. The use of computerised tomography in dislocation of the hip and femoral neck anteversion in children. J Bone Joint Surg Br. 1981;63:198208.

58. Reynolds D, Lucas J, Klaue K. Retroversion of the acetabulum. A cause of hip pain. J Bone Joint Surg Br. 1999;81:281-288.

59. Roach JW, Hobatho MC, Baker KJ, Ashman RB. Three-dimensional computer analysis of complex acetabular insufficiency. $J$ Pediatr Orthop. 1997;17:158-164.

60. Sharp IK. Acetabular dysplasia: the acetabular angle. $J$ Bone Joint Surg Br. 1961;43:268-272.

61. Siebenrock KA, Scholl E, Lottenbach M, Ganz R. Bernese periacetabular osteotomy. Clin Orthop Relat Res. 1999;363:9-20.

62. Steppacher SD, Tannast M, Ganz R, Siebenrock KA. Mean 20year followup of Bernese periacetabular osteotomy. Clin Orthop Relat Res. 2008;466:1633-1644.

63. Tallroth K, Lepistö J. Computed tomography measurement of acetabular dimensions: normal values for correction of dysplasia. Acta Orthop. 2006;77:598-602.

64. Thomas SR, Wedge JH, Salter RB. Outcome at forty-five years after open reduction and innominate osteotomy for late-presenting developmental dislocation of the hip. J Bone Joint Surg Am. 2007;89:2341-2350.

65. Tönnis D. Normal values of the hip joint for the evaluation of X-rays in children and adults. Clin Orthop Relat Res. 1976;119:39-47.

66. Tönnis D, Heinecke A. Acetabular and femoral anteversion: relationship with osteoarthritis of the hip. J Bone Joint Surg Am. 1999;81:1747-1770.

67. Totty WG, Vannier MW. Complex musculoskeletal anatomy: analysis using three dimensional surface reconstruction. Radiology. 1984;150:173-177.

68. Troelsen A, Elmengaard B, Soballe K. Medium-term outcome of periacetabular osteotomy and predictors of conversion to total hip replacement. J Bone Joint Surg Am. 2009;91:2169-2179.

69. Trousdale RT, Ekkernkamp A, Ganz R, Wallrichs SL. Periacetabular and intertrochanteric osteotomy for the treatment of osteoarthrosis in dysplastic hips. J Bone Joint Surg Am. 1995;77:73-85.

70. Vannier MW, Totty WG, Stevens WG, Weeks PM, Dye DM, Daum WJ, Gilula LA, Murphy WA, Knapp RH. Musculoskeletal applications of three-dimensional surface reconstructions. Orthop Clin North Am. 1985;16:543-555.

71. Visser JD, Jonkers A, Hillen B. Hip joint measurements with computerized tomography. J Pediatr Orthop. 1982;2:143-146.

72. Weiner LS, Kelley MA, Ulin RI, Wallach D. Development of the acetabulum and hip: computed tomography analysis of the axial plane. J Pediatr Orthop. 1993;13:421-425.

73. Wiberg G. Studies on dysplastic acetabula and congenital subluxation of the hip joint: with special reference to the complication of osteoarthritis. Acta Orthop Scand. 1939;83(Suppl 58):1-135.

74. Zou Z, Chavez-Arreola A, Mandal P, Board TN, Alonso-Rasgado T. Optimization of the position of the acetabulum in a ganz periacetabular osteotomy by finite element analysis. J Orthop Res. 2013;31:472-479. 